\title{
Community-based health efforts for the prevention of falls in the elderly
}

\author{
This article was published in the following Dove Press journal: \\ Clinical Interventions in Aging \\ 20 December 2010 \\ Number of times this article has been viewed
}

\section{Alan Hanley' \\ Carmel Silke ${ }^{2}$ \\ John Murphy ${ }^{3}$}

'Department of Medicine, Letterkenny General Hospital, Letterkenny, Co Donegal, Ireland; ' 2 Department of Rheumatology, Our Lady's Hospital Manorhamilton, Manorhamilton, Co Leitrim, Ireland; ${ }^{3}$ Department of Medicine, Castlebar, Co Mayo, Ireland

Correspondence: Alan Hanley Department of Medicine, Letterkenny General Hospital, Letterkenny, Co

Donegal, Ireland

Tel +35374 9l25888

Email alanhanley@gmail.com
Abstract: Falls are a major public health problem in the elderly population. The associated health care cost is great. It has therefore become an important public health matter to evaluate those interventions that might be effective in reducing the risk of falls. Risk factors that predict an increased risk of falling are described. We discuss interventions that can be employed in the community to reduce the risk of falls and associated injuries by discipline, including physiotherapy, occupational therapy, and physician-led interventions. We also discuss the cost-effectiveness of such interventions.

Keywords: fall, fracture, prevention, public health

\section{Introduction}

Falls are a major public health problem in the elderly population. Every year accidental falls occur in nearly one-third of those aged more than 65 years, with $10 \%$ of these falls resulting in serious injury. ${ }^{1}$ Falls lead to reduced levels of independence, poorer quality of life, and high levels of anxiety. ${ }^{2}$

The associated health care cost is great. In the United States, more than 2.6 million people aged above 65 years suffer a fall requiring medical attention annually, resulting in over US\$19 billion in medical costs. ${ }^{3}$ In the UK, nearly 650,000 people above the age of 60 years fall and require a visit to hospital every year and the annual cost approaches $£ 1$ billion. ${ }^{4}$ In one area of Australia, falls in those aged above 65 years cost A $\$ 83$ million annually, ${ }^{5}$ while the cost of fall-related admissions to one Irish hospital for 1 year was $€ 11$ million. ${ }^{6} \mathrm{~A}$ recent review found the average cost of a fall requiring hospitalization to be US\$26,483. ${ }^{7}$

As the population ages, an increasing number of people are at risk of falls and fallrelated injuries. It has therefore become an important public health matter to evaluate those interventions that might be effective in reducing the risk of falls. Many of these interventions can be safely delivered in a cost-effective manner outside the hospital setting. We discuss measures aimed at reducing rates of falls and fall-related injuries that can be employed in the community to help alleviate the health care burden associated with falls in the elderly.

\section{Methods}

PubMed, ScienceDirect, and the Cochrane databases were searched for high-quality review articles and prospective trials. Observational data and retrospective trials have been referenced where appropriate. Risk factors and methods of assessing risk 
in order to determine who will be most likely to benefit are first addressed. We describe interventions that can be employed in the community and in high-risk groups to reduce risk of falls and associated injuries by discipline, including physiotherapy, occupational therapy, and physician-led interventions. We also discuss some of the available data describing cost-effectiveness of such programs.

\section{Risk factor assessment}

A variety of interventions has been identified that may reduce risk of falling or suffering a fracture. However, not every intervention is effective in every patient group. ${ }^{8} \mathrm{An}$ important part of developing a cost-effective program that works is identifying those most likely to benefit from it, for example, those at greatest risk of falling.

A number of individual features in the patients' history are helpful in identifying an increased risk of falling. A history of falling is one of the strongest predictors of suffering a fall in the future. ${ }^{1}$ Gait problems, age, depression, cognitive impairment, and psychotropic medication use also indicate increased risk of falls among elderly community dwellers. ${ }^{9-11}$ A meta-analysis confirms that balance impairment imparts a moderately increased risk of falling. ${ }^{12}$

Early work from the MEDOS group - a Europe-wide study examining the epidemiology of hip fractures - found that individual factors associated with high-risk falls were difficult to identify. A diverse range of patient and environmental features associated with falls that cause fractures was described. This led the authors to the conclusion that developing a widely applicable program for risk factor modification would be costly and difficult. ${ }^{13}$ However, there is accumulating evidence that with increasing numbers of risk factors, there is an increased risk of falling. ${ }^{9} 10$

\section{Prediction tools}

A number of tools have been studied for their value in predicting whether a person is likely to fall or not. Tromp et al developed a risk stratification tool using four predictors of increased risk of falls in a prospective cohort study. Those predictors for increased risk of recurrent falls were previous falls, urinary incontinence, visual impairment, and functional limitations. ${ }^{14}$ Reaction times, the Berg balance scale, activities-specific balance confidence scale, and postural sway have all been found to be valid and reliable, and can be used to identify individuals at increased risk of falling. ${ }^{15,16}$

One review of 20 risk stratification tools described widely varying sensitivity and specificity, but a sufficient number were useful enough to recommend against developing yet more instruments. ${ }^{17}$ Although primarily aimed at institutional use, they may be useful in identifying those at increased risk of falls postdischarge. Tools such as the 6-minute walk test have also been validated in the community, with the caveat that validation studies have not been performed in all settings or across all subpopulations, such as those with cognitive impairment. ${ }^{18}$

\section{Exercise}

Home-based exercise programs have been shown to improve standard measures of balance, an effect that is preserved over time. ${ }^{19}$ There is good evidence that muscle strengthening and balance retraining are effective in reducing falls and fallrelated injuries, both individually and as part of a multidisciplinary approach. The randomized controlled FAME study compared an individually tailored exercise program with instructions for exercising at home. The study found a $54 \%$ reduction in falls among women aged above 65 years receiving the exercise program. A reduction in death, hospitalization, or transfer to nursing home care at 3-year follow-up was also seen. ${ }^{20}$ Tinetti et al reported a prospective trial looking at exercise as part of a multifaceted approach to reducing falls, including adjustment to medications and behavioral instruction. The incidence of falls in the intervention group ( $\mathrm{n}=153)$ was reduced from $47 \%$ to $35 \%(P=0.04)$ after 1 year of follow-up. ${ }^{21}$ Exercise aimed at reducing falls can be delivered at home, and has been shown in a meta-analysis to be effective in this setting. ${ }^{22}$

A meta-analysis of seven randomized trials found that planned exercise programs reduce the incidence of falls in an at-risk population. ${ }^{23}$ This finding is supported by a Cochrane review by Gillespie et al, which found that multicomponent group exercise reduces rate and risk of falling. ${ }^{24}$ In addition, Sherrington et al identified particular features of programs that are effective at reducing rates of falling. Those features were a greater total amount of exercise, and an emphasis on more challenging balance exercises..$^{25}$ These interventions are particularly effective at reducing falls in community dwellers, and may be beneficial even in the very elderly (those above 85 years of age). ${ }^{22,26}$ Such exercise programs can be delivered in the home by a trained nurse and have been shown to be cost-effective. ${ }^{27}$

\section{The need for a step-down program}

A step-down program is a period of less-intensive therapy after the initial intervention has taken place. There is a rationale behind exploring the possible benefits of such a program in reducing risk of falls. For example, a randomized trial of 
elderly individuals in Finland compared an intensive balance retraining program as part of a multifactorial intervention to a single counseling session. A significant reduction in the incidence of falls requiring medical treatment was seen on completion of a 12-month intervention, but not at 3-year follow-up, suggesting the need for continued intervention, possibly in the form of a step-down program..$^{28,29}$ A similar prospective French study demonstrated no significant reduction in falls despite an improvement in tests of balance following 10 sessions of exercise compared with no exercise. However, falls occurred at a later time in the intervention group, suggesting an early benefit that is not sustained once the exercise program has ended. ${ }^{30}$

One of the only described step-down programs, a study of 200 elderly community dwellers in Hong Kong, found a significant improvement in balance and reduction in falls and fall-related injuries following weekly attendance at a multidisciplinary falls-prevention clinic for 12 weeks. The falls clinic was supplemented with a 9-month step-down program which included a weekly exercise class. The authors note that this step-down program is important in maintaining the initial benefit seen with the falls clinic. ${ }^{31}$ A community falls-prevention program based on exercise and education is operational in Falun, Sweden. Bjerre and Schelp found the program to be effective in reducing fall-related injuries, but observed a waning effect over time. The authors concluded that continuous reinforcement is necessary to maintain the program's effectiveness. ${ }^{32}$

\section{Tai-Chi}

As a community intervention, regular Tai-Chi has been proposed as a practical method of delivering regular exercise. Randomized trials have come to differing conclusions regarding its effectiveness. Tai-Chi improves muscle strength and measures of balance, but programs see high withdrawal and low adherence rates. ${ }^{33-35} \mathrm{~A}$ more recent meta-analysis of Tai-Chi included nine randomized trials, with the conclusion that there is insufficient evidence to recommend Tai-Chi as an effective method of preventing falls. ${ }^{36}$

\section{Future considerations}

A review of current physiotherapy practice in the UK has shown that among those who have fallen and suffered a fracture, those that have suffered a non-hip fracture (for example, a wrist fracture) receive appropriate evaluation and secondary prevention exercises less often than those who have suffered a hip fracture. Levels of implementation among neither group met with national guidelines. ${ }^{37}$ Furthermore, current levels of knowledge among this group of health professionals may be insufficient to meet the demands of a well-functioning exercise program specifically targeted at prevention of falls. ${ }^{38}$ For future planning, one component of a comprehensive multifactorial falls-prevention program might involve targeting education at trainee exercise professionals.

\section{Occupational therapy}

Home hazards are significantly associated with falls and fall-related injuries. ${ }^{39}$ One review highlighted environmentrelated factors, poor balance, and dizziness as being the most commonly reported individual causes for falls. ${ }^{40} \mathrm{~A}$ home visit by an occupational therapist with recommendations for home hazard modification is a well-described component of a multidisciplinary falls-prevention clinic, and has been shown to reduce falls rates in those at high risk. ${ }^{24,41}$ Home modification may not reduce rates of falling in those not at high risk. In addition, a Cochrane review found that this intervention is not effective in injury prevention, despite a reduction in rate of falls. ${ }^{42}$

Salkeld et al have demonstrated that home hazard modification is cost-effective in those who have fallen within the previous 12 months, while Frick et al report that home modification provides the best value in reduction of falls. ${ }^{43,44}$ Early work suggests that self-reporting of home hazards using an adapted version of a tool employed by professionals correlates well with risk of falls. ${ }^{45}$ This would likely reduce costs further, while promoting a proactive approach to reducing risk of falls.

In terms of reducing injuries associated with falls, hip protectors have been previously advocated as reducing hip fracture incidence in those at greatest risk. ${ }^{46}$ Compliance among elderly individuals dwelling in high-risk community is very poor however, and they have not proven effective in this group. ${ }^{47}$

\section{Medical intervention}

A number of comparatively simple medical interventions are effective at reducing rates of falling in the general population and in those at high risk, and could be implemented by general practitioners. Vitamin D supplementation has been shown to significantly reduce risk of falls in elderly individuals dwelling in communities, provided dietary calcium intake is $512 \mathrm{mg} /$ day or more. ${ }^{48} \mathrm{~A}$ randomized controlled trial has shown that withdrawal of psychotropic agents has been shown to reduce the risk of falling; this is supported by a large amount of observational data. ${ }^{49,50}$ Use of sedatives or antidepressants is associated with an increased rate 
of falling, as is polypharmacy, highlighting the need for a judicious risk-benefit analysis in those at an increased risk of falling. ${ }^{51,52}$ A randomized trial evaluating an initiative to modify prescribing patterns among general practitioners, for example, reduction of nonsteroidal anti-inflammatory drug use, found a reduced rate of falls and injuries at 12 months. $^{53}$

Other measures effective at reducing risk of falls in particular settings include referral for cataract surgery and insertion of a dual-chamber cardiac pacemaker if indicated. ${ }^{54,55}$

In addition to the above measures aimed at reducing risk of falls, medical intervention can help reduce morbidity by reducing fall-related injury. Studies examining whether combined calcium and vitamin $\mathrm{D}$ reduce fractures in the community have produced mixed results; compliance may be the major confounder as the intervention has proven beneficial when treatment is supervised. ${ }^{56}$ Risedronate has been shown to reduce the risk of suffering a hip fracture in elderly women with osteoporosis. ${ }^{57}$

\section{Use of education in fall prevention}

An education program aimed at increasing awareness of the risks associated with falling can have beneficial effects. A Swedish study carried out in a town of 80,000 people targeted certain groups such as opticians, podiatrists, and operators of gyms. The study demonstrated a reduction in falls and fall-related disability. The cost incurred by falls was also reduced to a greater extent than that seen nationally in Sweden. The reduction in hip fractures seen in hospital was $48 \%{ }^{58}$

A prospective study has shown that simple education alone is ineffective at reducing the incidence of falls. ${ }^{59}$ Peer-delivered education may promote greater participation, and has been shown to improve falls-prevention awareness. Participants have a more proactive approach to preventing recurrent falls, although this intervention has not been shown to lead to a reduction in falls. ${ }^{60}$

\section{Adherence rates}

Education may attenuate the problem of low levels of acceptance of fall-management strategies seen among those at greatest risk. In a survey $(n=5440)$ to determine how willing elderly people would be to participate in falls-prevention activities, more than $40 \%$ of people would definitely not attend group sessions of strength and balance retraining. ${ }^{61}$ Larsen et al $(n=7543)$ report that never-married males aged 66-84 years accept relatively simple falls-prevention measures as little as $30 \%$ of the time. The figures for widows of the same age, while greater at $57 \%$, indicate that a major stumbling block to implementing a successful communitybased strategy exists. ${ }^{62}$ Even a randomized trial achieved participation rates of just over $60 \%$ for attendance at exercise sessions. $^{28}$

\section{Cost-effectiveness}

Community-based falls-prevention programs is an attractive proposition. Approaches to delivering a multidisciplinary falls-prevention program have been described and are available to model future programs; their uptake has been advocated by the Center for Disease Control in the United States following a review of 20 years of efforts to reduce the incidence of falls and the associated costs. ${ }^{63-65}$ The interventions are generally well tolerated; the potential gain in terms of health economics is great. In New South Wales, Australia, such a multidisciplinary program has been shown to have a benefit to cost ratio of 20.6:1, having generated savings of up to $\mathrm{A} \$ 16.9$ million over a 4 -year period, in a population of $400,000 .{ }^{66}$ A systematic review found single-factor interventions, such as the Otago Exercise Program in New Zealand to provide the best value for money, while also finding costeffectiveness in customized, multifactorial interventions and home safety measures. ${ }^{67}$

Despite potential gains including cost reduction, fallsprevention programs have not become a widely used tool in modern health care. Moller postulates that difficulty in proving benefit coupled with a low political profile contributes to the lack of funding generally awarded to such programs. ${ }^{68}$

\section{Discussion}

A variety of interventions has been studied widely for the reduction of risk of falls in the community. Although some interventions have shown benefit when studied in isolation, several trials, randomized trials and meta-analyses, have confirmed the efficacy of a multifactorial falls-prevention program. The number needed to treat to prevent one fall/year was 32 for a single intervention (home modification) compared with seven for a multidisciplinary intervention in one randomized trial. ${ }^{21,69-74} \mathrm{~A}$ meta-analysis has found that single interventions may be as beneficial as a multicomponent intervention, provided the single intervention is targeted at a particular risk factor such as poor balance. ${ }^{75}$

Effective interventions include the following:

- Muscle strengthening and balance retraining as part of an individually tailored exercise program

- A home visit by an occupational therapist with recommendations for home hazard modification can reduce 
rates of falling in high-risk groups, for example, those with a history of falling

- A prescribing modification course for general practitioners

- Withdrawal of psychotropic medications where possible and referral for cataract surgery or cardiac pacemaker insertion where indicated

Potentially useful interventions that warrant further study include Tai-Chi exercise classes, the use of step-down programs, and public-awareness campaigns particularly targeted at community workers likely to encounter those at high risk of falling, for example, opticians. Education and reinforcement should be evaluated as a means of improving adherence to interventions proven to be effective.

Finally, controversies persist with regard to the strength of evidence supporting current interventions. ${ }^{76}$ McClure et al found population-based programs for reducing falls to be efficacious but point out that further randomized trials are needed to increase the level of evidence available. ${ }^{77}$

\section{Conclusions}

Multidisciplinary falls-prevention strategies have been shown to be effective, while single intervention strategies are effective in high-risk populations. There is evidence to suggest that population-based interventions to reduce rates of falls are cost-effective.

\section{Disclosure}

The authors report no conflicts of interest in this work.

\section{References}

1. Ganz DA, Bao Y, Shekelle PG, Rubenstein LZ. Will my patient fall? JAMA. 2007;297(1):77-86.

2. Kumar S, Vendhan G, Awasthi S, Tiwari M, Sharma VP. Relationship between fear of falling, balance impairment and functional mobility in community dwelling elderly. Indian Journal of Physical Medicine and Rehabilitation. 2008;19(2):48-52.

3. Stevens JA, Corso PS, Finkelstein EA, Miller TR. The costs of fatal and non-fatal falls among older adults. Inj Prev. 2006;12(5):290-295.

4. Scuffham P, Chaplin S, Legood R. Incidence and costs of unintentional falls in older people in the United Kingdom. $J$ Epidemiol Community Health. 2003;57(9):740-744.

5. Hendrie D, Hall SE, Legge M, Arena G. Injury in Western Australia: The Health System Cost of Falls in Older Adults in Western Australia. Perth, Western Australia: Western Australian Government; 2003.

6. Cotter PE, Timmons S, O'Connor M, Twomey C, O’Mahony D. The financial implications of falls in older people for an acute hospital. Ir $J$ Med Sci. 2006;175(2):11-13.

7. Davis JC, Robertson MC, Ashe MC, Liu-Ambrose T, Khan KM, Marra CA. International comparison of cost of falls in older adults living in the community: a systematic review. Osteoporos Int. 2010;21(8): 1295-1306.

8. Kannus P, Sievänen H, Palvanen M, Järvinen T, Parkkari J. Prevention of falls and consequent injuries in elderly people. Lancet. 2005; 366(9500):1885-1893.
9. Stalenhoef PA, Diederiks JP, Knottnerus JA, Kester AD, Crebolder HF. A risk model for the prediction of recurrent falls in community-dwelling elderly: a prospective cohort study. J Clin Epidemiol. 2002;55(11): 1088-1094.

10. Delbaere K, Close JC, Heim J, et al. A multifactorial approach to understanding fall risk in older people. J Am Geriatr Soc. 2010;58(9): 1679-1685.

11. Leipzig RM, Cumming RG, Tinetti ME. Drugs and falls in older people: a systematic review and meta-analysis: I. Psychotropic drugs. $J \mathrm{Am}$ Geriatr Soc. 1999;47(1):30-39.

12. Muir SW, Berg K, Chesworth B, Klar N, Speechley M. Quantifying the magnitude of risk for balance impairment on falls in communitydwelling older adults: a systematic review and meta-analysis. $J$ Clin Epidemiol. 2010;63(4):389-406.

13. Allander E, Gullberg B, Johnell O, Kanis JA, Ranstam J, Elffors L. Circumstances around the fall in a multinational hip fracture risk study: a diverse pattern for prevention. MEDOS Study Group. Mediterranean Osteoporosis Study. Accid Anal Prev. 1998;30(5): 607-616.

14. Tromp AM, Pluijm SM, Smit JH, Deeg DJ, Bouter LM, Lips P. Fall-risk screening test: a prospective study on predictors for falls in communitydwelling elderly. J Clin Epidemiol. 2001;54(8):837-844.

15. Lajoie Y, Gallagher SP. Predicting falls within the elderly community: comparison of postural sway, reaction time, the Berg balance scale and the activities-specific balance confidence (ABC) scale for comparing fallers and non-fallers. Arch Gerontol Geriatr. 2004;38(1): $11-26$.

16. Filiatrault J, Gauvin L, Fournier M, et al. Evidence of the psychometric qualities of a simplified version of the activities-specific balance confidence scale for community-dwelling seniors. Arch Phys Med Rehabil. 2007;88(5):664-672.

17. Perell KL, Nelson A, Goldman RL, Luther SL, Prieto-Lewis N, Rubenstein LZ. Fall risk assessment measures: an analytic review. J Gerontol A Biol Sci Med Sci. 2001;56(12):M761-M766.

18. Scott V, Votova K, Scanlan A, Close J. Multifactorial and functional mobility assessment tools for fall risk among older adults in community, home-support, long term and acute care settings. Age Ageing. 2007; 36(2):130-139.

19. Korpelainen R, Keinänen-Kiukaanniemi S, Nieminen P, Heikkinen J, Väänänen K, Korpelainen J. Long-term outcomes of exercise: follow-up of a randomized trial in older women with osteopenia. Arch Intern Med. 2010;170(17):1548-1556.

20. Skelton D, Dinan S, Campbell M, Rutherford O. Tailored group exercise (Falls Management Exercise - FaME) reduces falls in communitydwelling older frequent fallers (an RCT). Age Ageing. 2005;34(6): 636-639.

21. Tinetti ME, Baker DI, McAvay G, et al. A multifactorial intervention to reduce the risk of falling among elderly people living in the community. N Engl J Med. 1994;331(13):821-827.

22. Robertson MC, Campbell AJ, Gardner MM, Devlin N. Preventing injuries in older people by preventing falls: a meta-analysis of individual-level data. J Am Geriatr Soc. 2002;50(5):905-911.

23. Province MA, Hadley EC, Hornbrook MC, et al. The effects of exercise on falls in elderly patients: a preplanned meta-analysis of the FICSIT trials. Frailty and injuries: cooperative studies of intervention techniques. JAMA. 1995;273(17):1341-1347.

24. Gillespie LD, Robertson MC, Gillespie WJ, et al. Interventions for preventing falls in older people living in the community. Cochrane Database Syst Rev. 2009;2:CD007146.

25. Sherrington C, Whitney JC, Lord SR, Herbert RD, Cumming RG, Close JC. Effective exercise for the prevention of falls: a systematic review and meta-analysis. J Am Geriatr Soc. 2008;56(12):2234-2243.

26. Luukinen H, Lehtola S, Jokelainen J, Väänänen-Sainio R, Lotvonen S, Koistinen P. Pragmatic exercise-oriented prevention of falls among the elderly: a population-based, randomized, controlled trial. Prev Med. 2007;44(3):265-271. 
27. Robertson MC, Devlin N, Gardner MM, Campbell AJ. Effectiveness and economic evaluation of a nurse delivered home exercise programme to prevent falls. 1: Randomised controlled trial. BMJ.2001;322(7288): 697-701.

28. Salminen M, Vahlberg T, Sihvonen S, et al. Effects of risk-based multifactorial fall prevention on postural balance in the communitydwelling aged: a randomized controlled trial. Arch Gerontol Geriatr. 2009;48(1):22-27.

29. Salminen M, Vahlberg T, Kivelä SL. The long-term effect of a multifactorial fall prevention programme on the incidence of falls requiring medical treatment. Public Health. 2009;123(12):809-813.

30. Cornillon E, Blanchon MA, Ramboatsisetraina P, et al. Effectiveness of falls prevention strategies for elderly subjects who live in the community with performance assessment of physical activities (before-after). Ann Readapt Med Phys. 2002;45(9):493-504.

31. Sze PC, Cheung WH, Lam PS, Lo HSD, Leung KS, Chan T. The efficacy of a multidisciplinary falls prevention clinic with an extended step-down community program. Arch Phys Med Rehabil. 2008;89(7): 1329-1334

32. Bjerre B, Schelp L. The community safety approach in Falun, Swedenis it possible to characterise the most effective prevention endeavours and how long-lasting are the results? Accid Anal Prev. 2000;32(3): 461-470.

33. Logghe IH, Zeeuwe PE, Verhagen AP, et al. Lack of effect of Tai Chi Chuan in preventing falls in elderly people living at home: a randomized clinical trial. J Am Geriatr Soc. 2009;57(1):70-75.

34. Logghe IH, Verhagen AP, Rademaker AC, et al. Explaining the ineffectiveness of a Tai Chi fall prevention training for community-living older people: a process evaluation alongside a randomized clinical trial (RCT). Arch Gerontol Geriatr. 2010; Jun 6 [Epub ahead of print]. doi: 10.1016/j.archger.2010.05.013.

35. Li F, Harmer P, Fisher KJ, et al. Tai Chi and fall reductions in older adults: a randomized controlled trial. J Gerontol A Biol Sci Med Sci. 2005;60(2):187-194.

36. Logghe IH, Verhagen AP, Rademaker AC, et al. The effects of Tai Chi on fall prevention, fear of falling and balance in older people: a meta-analysis. Prev Med. 2010;51(3-4):222-227.

37. Goodwin V, Martin FC, Husk J, Lowe D, Grant R, Potter J. The national clinical audit of falls and bone health - secondary prevention of falls and fractures: a physiotherapy perspective. Physiotherapy. 2010;96(1):38-43.

38. Sturnieks DL, Finch CF, Close JC, Tiedemann A, Lord SR, Pascoe DA. Exercise for falls prevention in older people: assessing the knowledge of exercise science students. J Sci Med Sport. 2010;13(1):59-64.

39. Leclerc BS, Bégin C, Cadieux E, et al. Relationship between home hazards and falling among community-dwelling seniors using homecare services. Rev Epidemiol Sante Publique. 2010;58(1):3-11.

40. Rubenstein LZ. Falls in older people: epidemiology, risk factors and strategies for prevention. Age Ageing. 2006;35 Suppl 2:ii37-ii41.

41. Karinkanta S, Piirtola M, Sievänen H, Uusi-Rasi K, Kannus P. Physical therapy approaches to reduce fall and fracture risk among older adults. Nat Rev Endocrinol. 2010;6(7):396-407.

42. Lyons RA, John A, Brophy S, et al. Modification of the home environment for the reduction of injuries. Cochrane Database Syst Rev. 2006;4:CD003600.

43. Salkeld G, Cumming RG, O'Neill E, Thomas M, Szonyi G, Westbury C. The cost effectiveness of a home hazard reduction program to reduce falls among older persons. Aust N Z J Public Health. 2000;24(3): 265-271.

44. Frick KD, Kung JY, Parrish JM, Narrett MJ. Evaluating the costeffectiveness of fall prevention programs that reduce fall-related hip fractures in older adults. J Am Geriatr Soc. 2010;58(1):136-141.

45. Hassani Mehraban A, Mackenzie LA, Byles JE. A self-report home environment screening tool identified older women at risk of falls. $J$ Clin Epidemiol. 2010; Jun 14 [Epub ahead of print].
46. Honkanen LA, Mushlin AI, Lachs M, Schackman BR. Can hip protector use cost-effectively prevent fractures in community-dwelling geriatric populations? J Am Geriatr Soc. 2006;54(11):1658-1665.

47. Gillespie WJ, Gillespie LD, Parker MJ. Hip protectors for preventing hip fractures in older people. Cochrane Database Syst Rev. 2010;10:CD001255.

48. Dukas L, Bischoff HA, Lindpaintner LS, et al. Alfacalcidol reduces the number of fallers in a community-dwelling elderly population with a minimum calcium intake of more than $500 \mathrm{mg}$ daily. $J$ Am Geriatr Soc. 2004;52(2):230-236.

49. Campbell AJ, Robertson MC, Gardner MM, Norton RN, Buchner DM. Psychotropic medication withdrawal and a home-based exercise program to prevent falls: a randomized, controlled trial. $J$ Am Geriatr Soc. 1999;47(7):850-853.

50. Hartikainen S, Lonnroos E, Louhivuori K. Medication as a risk factor for falls: critical systematic review. J Gerontol A Biol Sci Med Sci. 2007;62(10):1172-1181.

51. Woolcott JC, Richardson KJ, Wiens MO, et al. Meta-analysis of the impact of 9 medication classes on falls in elderly persons. Arch Intern Med. 2009;169(21):1952-1960.

52. Leipzig RM, Cumming RG, Tinetti ME. Drugs and falls in older people: a systematic review and meta-analysis: II. Cardiac and analgesic drugs. J Am Geriatr Soc. 1999;47(1):40-50.

53. Pit SW, Byles JE, Henry DA, Holt L, Hansen V, Bowman DA. A quality use of medicines program for general practitioners and older people: a cluster randomised controlled trial. Med J Aust. 2007;187(1):23-30.

54. Harwood RH, Foss AJ, Osborn F, Gregson RM, Zaman A, Masud T. Falls and health status in elderly women following first eye cataract surgery: a randomised controlled trial. Br J Ophthalmol. 2005;89(1): 53-59.

55. Kenny RA, Richardson DA, Steen N, Bexton RS, Shaw FE, Bond J. Carotid sinus syndrome: a modifiable risk factor for nonaccidental falls in older adults (SAFE PACE). J Am Coll Cardiol. 2001;38(5): 1491-1496.

56. Lips P, Bouillon R, van Schoor NM, et al. Reducing fracture risk with calcium and vitamin D. Clin Endocrinol (Oxf). 2010;73(3): 277-285.

57. McClung MR, Geusens P, Miller PD, et al. Effect of risedronate on the risk of hip fracture in elderly women. Hip Intervention Program Study Group. N Engl J Med. 2001;344(5):333-340.

58. Larsson TJ, Hägvide ML, Svanborg M, Borell L. Falls prevention through community intervention - a Swedish example. Saf Sci. 2010; 48(2):204-208.

59. Rucker D, Rowe BH, Johnson JA, et al. Educational intervention to reduce falls and fear of falling in patients after fragility fracture: results of a controlled pilot study. Prev Med. 2006;42(4):316-319.

60. Deery HA, Day LM, Fildes BN. An impact evaluation of a falls prevention program among older people. Accid Anal Prev. 2000;32(3): 427-433.

61. Yardley L, Kirby S, Ben-Shlomo Y, Gilbert R, Whitehead S, Todd C. How likely are older people to take up different falls prevention activities? Prev Med. 2008;47(5):554-558.

62. Larsen ER, Mosekilde L, Foldspang A. Determinants of acceptance of a community-based program for the prevention of falls and fractures among the elderly. Prev Med. 2001;33(2 Pt 1):115-119.

63. Jackson R, Fantom J. A pilot scheme for an integrated falls prevention service. J Orthop Nurs. 2002;6(4):204-210.

64. Hanley A, Ali MT, Murphy J. Early experience of a fall and fracture prevention clinic at Mayo General Hospital. Ir J Med Sci. 2010;179(2): 277-278.

65. Sleet DA, Moffett DB, Stevens J. CDC's research portfolio in older adult fall prevention: a review of progress, 1985-2005, and future research directions. J Safety Res. 2008;39(3):259-267.

66. Beard J, Rowell D, Scott D, et al. Economic analysis of a communitybased falls prevention program. Public Health. 2006;120(8):742-751. 
67. Davis JC, Robertson MC, Ashe MC, Liu-Ambrose T, Khan KM, Marra CA. Does a home-based strength and balance programme in people aged $\geq 80$ years provide the best value for money to prevent falls? A systematic review of economic evaluations of falls prevention interventions. Br J Sports Med. 2010;44(2):80-89.

68. Moller J. Current costing models: are they suitable for allocating health resources? The example of fall injury prevention in Australia. Accid Anal Prev. 2005;37(1):25-33.

69. Salminen MJ, Vahlberg TJ, Salonoja MT, Aarnio PT, Kivelä SL. Effect of a risk-based multifactorial fall prevention program on the incidence of falls. J Am Geriatr Soc. 2009;57(4):612-619.

70. Close J, Ellis M, Hooper R, Glucksman E, Jackson S, Swift C. Prevention of falls in the elderly trial (PROFET): a randomised controlled trial. Lancet. 1999;353(9147):93-97.

71. Moore M, Williams B, Ragsdale S, et al. Translating a multifactorial fall prevention intervention into practice: a controlled evaluation of a fall prevention clinic. J Am Geriatr Soc. 2010;58(2):357-363.

72. Sze PC, Cheung WH, Lam PS, Lo HS, Leung KS, Chan T. The efficacy of a multidisciplinary falls prevention clinic with an extended step-down community program. Arch Phys Med Rehabil. 2008;89(7): 1329-1334.
73. Chang JT, Morton SC, Rubenstein LZ, et al. Interventions for the prevention of falls in older adults: systematic review and meta-analysis of randomised clinical trials. BMJ. 2004;328(7441):680.

74. Clemson L, Cumming RG, Kendig H, Swann M, Heard R, Taylor K. The effectiveness of a community-based program for reducing the incidence of falls in the elderly: a randomized trial. J Am Geriatr Soc. 2004;52(9):1487-1494.

75. Campbell AJ, Robertson MC. Rethinking individual and community fall prevention strategies: a meta-regression comparing single and multifactorial interventions. Age Ageing. 2007;36(6):656-662.

76. Lamb SE, Jørstad-Stein EC, Hauer K, Becker C; Prevention of falls network Europe and outcomes consensus group. Development of a common outcome data set for fall injury prevention trials: the prevention of falls network Europe consensus. J Am Geriatr Soc. 2005;53(9):1618-1622.

77. McClure R, Turner C, Peel N, Spinks A, Eakin E, Hughes K. Populationbased interventions for the prevention of fall-related injuries in older people. Cochrane Database Syst Rev. 2005;1:CD004441.
Clinical Interventions in Aging

\section{Publish your work in this journal}

Clinical Interventions in Aging is an international, peer-reviewed journal focusing on evidence-based reports on the value or lack thereof of treatments intended to prevent or delay the onset of maladaptive correlates of aging in human beings. This journal is indexed on PubMed Central, MedLine, the American Chemical Society's 'Chemical

\section{Dovepress}

Abstracts Service' (CAS), Scopus and the Elsevier Bibliographic databases. The manuscript management system is completely online and includes a very quick and fair peer-review system, which is all easy to use. Visit http://www.dovepress.com/testimonials.php to read real quotes from published authors. 